\title{
A Study for Advanced Visualization of Sensing Data \& Meta Data based WSN
}

\author{
Hyukjun Choi, Byeongtae Ahn
}

\begin{abstract}
As the 5G environment is established due to the development of network and information and network technologies, wireless sensor network is drawing attention as a technology that will lead the information technology industry in the future. The sensor-based service must collect and process data recognized from various sensors and deliver information to users to understand. However, there is no research to visually express information about sensor resources to make it easier for users to understand. Therefore, this research proposes an efficient visualization model that is both realistic and economical. Then, we designed a scenario applied to real life and built a webpage.
\end{abstract}

Keywords: Sensor Network; Sensing Data; Metadata; IoT; RFID

\section{INTRODUCTION}

In recent years, with the development of sensor technology, the human-centered information society is rapidly transforming into a ubiquitous computing society in which information can be organically combined and utilized between objects beyond humans and computers. This is due to the view that sensor-based information is simply one of the technological changes in the IT sector. Based on the recognition of these issues and its importance, this paper presents the direction of the IT strategy for realizing a ubiquitous society[1]. In addition, we pointed out the environment of disaster management, logistics distribution, health welfare, agricultural, livestock, and fisheries and analyzed and presented how users' questions in each field will be composed based on this. In addition, ubiquitous technologies and application models that can be applied to innovate the above fields to be appropriate for a ubiquitous society were examined, and the sensor-based information was classified into sensing data and metadata. Finally, for efficient expression for users, visual components were analyzed and a webpage was implemented based on them[2] In this paper, we also built a webpage to research realistic and economical sensing service models and to efficiently provide users with the sensor-based information via the web in stages. Since the proposed content for the implementation plan's sensor-based webpage design includes various technical, institutional, and industrial considerations, various

Manuscript received on June 28, 2021.

Revised Manuscript received on July 01, 2021.

Manuscript published on August 30, 2021.

* Correspondence Author

Byeongtae Ahn*, Faculty of Division, Liberal \& Arts College, Anyang University, Anyang-shi, South Korea. Email: ahnbt@anyang.ac.kr

Hyukjun Choi, Department of International Logistics at Pyeongtaek University, South Korea.

(C) The Authors. Published by Blue Eyes Intelligence Engineering and Sciences Publication (BEIESP). This is an open access article under the CC BY-NC-ND license (http://creativecommons.org/licenses/by-nc-nd/4.0/) considerations that can appear in the real world have been fully utilized[3].

\section{RELATED WORKS}

\subsection{BcN (Broadband Convergence Network)}

A broadband convergence network is a next-generation telenetwork network that can provide various services integrated with voice and data by simplifying different networks such as PSTN, the Internet, ATM, private networks, and wireless networks into one common network[4]. The BcN is a network of concepts that combine wire and wireless, comprised of the entire network networks, from the subscriber terminal to the exchanger, in a packet-like system. High-quality services such as voice, data, and video can be provided to users in real time through integration infrastructure of wire-wireless anytime and anywhere[5]. The current network networks are separated from the Internet and wireless Internet, so even if it uses remote control services, it has different access depending on the device. However, in the $\mathrm{BcN}$ environment, wire/wireless is freely used at the convenience of users, allowing seamless network with high speed and broadband. In terms of service, all services such as voice, video, multimedia, and all forms of data services can be provided[6]. In other words, the $\mathrm{BcN}$-integrated network aims for convergence in the case of network technology and provides services in a ubiquitous environment that can be serviced anytime, anywhere, and in any way[7].

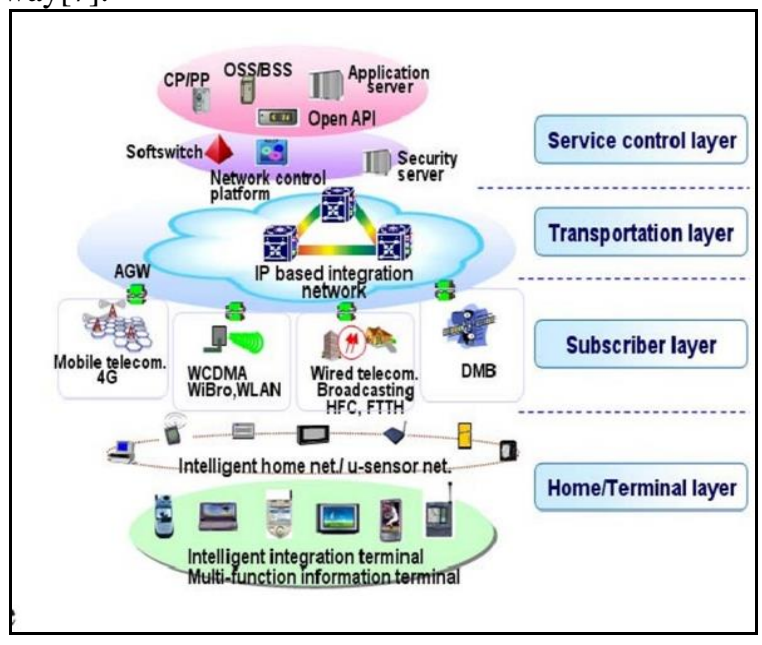

Fig. 1. BcN Structure Diagram

Fig. 1 is a diagram of $\mathrm{BcN}$ divided into service layer, transport network layer, subscriber loop network layer, and home/terminal layer.

Published By:

Blue Eyes Intelligence Engineering and Sciences Publication

(C) Copyright: All rights reserved.

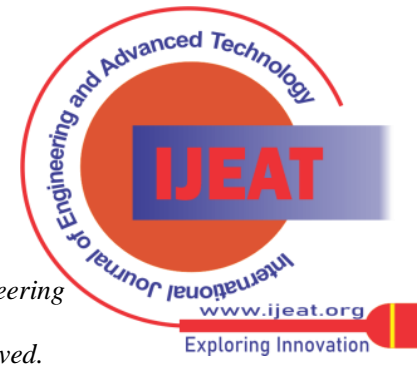


The service layer produces and manages various services and is composed of a server that performs roles such as application service creation, service control, and management with a network management system such as OSS/BSS, Open API platform, soft switch, etc[8]. The transport network layer, which exchanges and transmits information, consists of exchangers such as routers, ATMs, gateways, and large-capacity transmission equipment such as optical transmission equipment such as WDM, OXC, SDH. The subscriber network and home terminal layer, which support the subscriber's wired and wireless access processing, consists of various types of subscriber connections such as wire (xDSL, Ethernet, FTTx), wireless (mobile network, portable Internet, WLAN), broadcasting (HFC, DMB), home network (G/W), u-sensor network (UWB, smart tag), and integrated access terminal (Access Mediator) [9].

\subsection{RFID (Radio Frequency Identification)}

RFID (Radio Frequency Identification) is a technology system that inputs various types of identification information into micro-semiconductors, attaches them to goods, animals, and people, and collects and manages information through radio frequency[10]. RFID basically consists of a tag that stores various types of identification information in, a reader that can recognize the information stored in the RFID tag, and a data processing system that processes the information collected by the RFID reader. Using RFID, it is always possible to locate and process related information in real time, as well as to locate specific individuals or objects[11]. RFID is the core of the implementation of the ubiquitous environment and will greatly contribute to the development of related industries in the future. An RFID reader is a device that sends and receives tag information and transmits information collected from the tag to the network[12]. Currently, RFID readers have a characteristic that the range of application is limited because the recognition distance and recognition accuracy are affected by the antenna performance and the surrounding environment[13]. In the future, a reader that operates in various frequency bands such as $13.56 \mathrm{MHz}$, $900 \mathrm{MHz}$, and $433 \mathrm{MHz}$ and a reader that recognizes multiple codes such as EPC Code and ISO 18000 series codes are required. Therefore, it is expected that multi-band/multi-code readers and readers that can be interworked on various mobile devices will emerge[14].

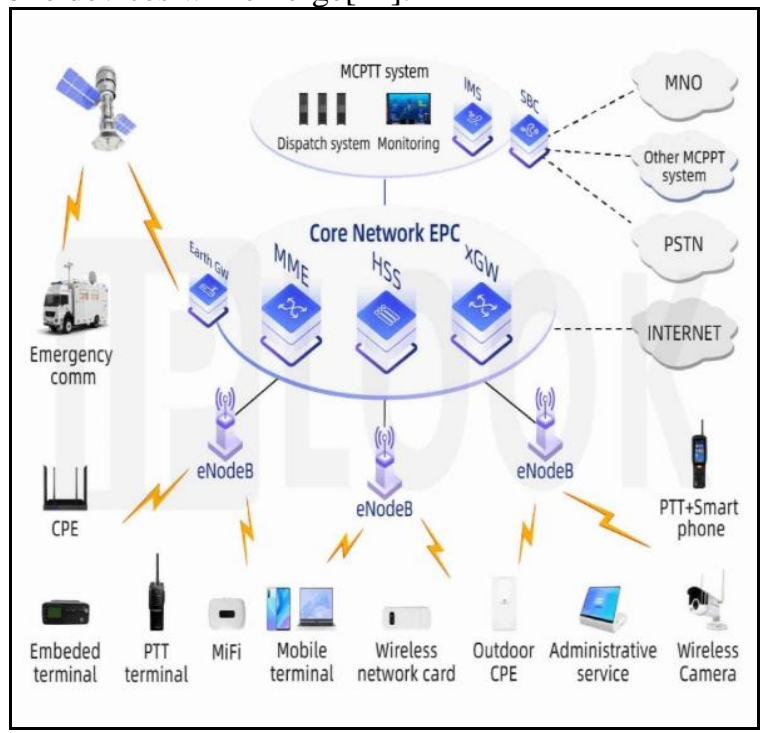

Fig. 2. EPC network Architecture
Fig. 2 is the structure of an EPC network for the application and management of standardized data using RFID. The biggest feature that distinguishes the RFID is based on past user recognition and the RFID currently under consideration is the existence of middleware and network interworking capabilities. For example, if you look at a company's network that uses RFID as an ID card, the recognized tag information is used only within the company for time and attendance management and access control, and it cannot be accessed from external networks[15]. And your ID card can only be recognized by the company you belong to and cannot be recognized by other companies' readers because the code systems are different. However, RFID information for future informatization of objects is given a global code that can be used anywhere in the world, and each code can be utilized in various applications through the Internet[16].

Middleware technology and network interworking technology are required for these functions, and various concepts are currently being introduced. RFID middleware is currently a conceptual technology, and its main concept presented by the MIT Auto-ID Center. EPC Global introduced concepts such as ONS (Object Naming Service) and ALE (Application Level Events) middleware. ONS uses the code embedded in RFID to find related information using the same concept as the IP address on the Internet, and various RFID services are provided through ALE middleware and EPC IS (Information Service[17]).

\section{SENSING SERVICE TYPE}

In this chapter, we analyze and compare several characteristics related to the configuration of the sensor-based key application services to predict use cases and propose an expected scenario to efficiently communicate information for each case to users. The sensor's main application service can be reconfigured into the main utilization service that provides convenience to users. In the case of administrative services, depending on the detailed service, it can be related to both the automation-safety classification and the life-culture classification of the sensor application service[18]. Looking at the possible application service scenarios for each sensor application service classification, it is divided into facility-transportation, distribution-logistics, environment, automation-safety, and life-culture[19].

\subsection{Public Administration Field}

Public administration refers to the next generation of public administration services that seek to improve the quality of life of citizens and efficient operation of the city by providing and monitoring information on facility management, establishing and operating systems, etc[20].

The information center consists of a public information control room and a security control room operated by the police. In the public information situation room, you can check the traffic conditions across the city at a glance, identify areas with a lot of traffic and the detour route, and provide the information to residents in real time through u-placards attached to each area[21].

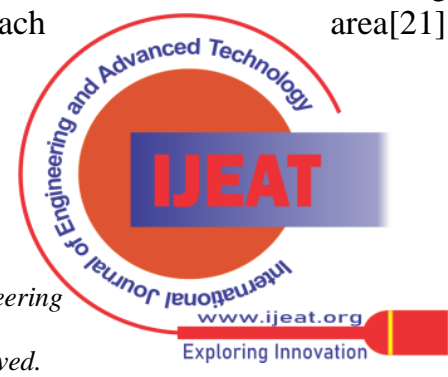


The situation room, which provides security services, is operated by the police and is integrated with the police situation room at the same time, and the CCTV (Closed-Circuit Television) in the city center is directly connected. In case of an emergency, one can press the emergency bell attached to the CCTV to capture the scene from the situation room and make a call[22]. In case of emergency situations such as fires or crime, the situation is automatically broadcast to various channels such as landline calls and cell phone messages, interlinked with the central GIS (geographic information system). And when a citizen who feels threatened presses an emergency bell installed in the city, the CCTVs installed in the vicinity automatically display the scenes to track the suspect's expected escape route, transmitting all situations to the police and at the same time. The ongoing service will be expanded to the media board, u-placard, u-parking, bus information system, unmanned vehicle stops control, vehicle number recognition, and external traffic information collection services after completing the first stage of the three-stage service[23].

\subsection{Economic Industry Field}

In the economic industry, the efficiency of various industries is maximized and convenient services are provided to users by optimizing equipment operation for facilities, establishing a logistics information system and an automated system for warehousing and reporting cargo. Workers in various industries may comprehensively identify the location of their facilities and optimize the operation of equipment to perform efficient tasks. In addition, the visibility of logistics can be secured by obtaining mobile information of various logistics in air, sea, and land, and information is provided in real time by the automation of receiving and shipping operations. The air cargo RFID infrastructure installs RFID readers at the export cargo terminal to check whether the export air cargo is received and whether airplanes are loaded and establishes the air logistics information system to manage it. Through this, delivery companies and consignors receive logistics movement information about their air cargo from the air information system to efficiently handle logistics management[24].

The RFID-based logistics information system installs RFID readers at major land logistics bases and highway toll gates and establishes the information system to manage them. When the information system is established, it can recognize the RFID tag of cargo vehicles and provide logistics information such as the location and time of passage to consignors and delivery companies, and it can be used for the automation of vehicle loading and unloading. The application base can be readjusted in the direction of optimizing the logistics flow through the ISP, and the highway toll gates are also judged as to whether it is applicable through technical review[25].

The RFID-based export and import custom clearance system attaches RFID tags to the import air cargo for the receiving and automation of the clarification work, and it establishes readers and the information system to manage them. Through this, import air cargo custom clearance is replaced with RFID tag recognition, and cargo mobile information is provided to consignors and delivery companies.

\section{DESIGN AND IMPLEMENTATION OF THE WEB SERVICE}

In this study, the overall main applied services and actual web service were established to express visual components of the USN based sensing and meta-data. Table 1 shows these types of meta-data. The meta-data includes the USIS (Ubiquitous Sensor Information System) being able to efficiently manage the USN meta-information resources, such as the purpose of sensor use, owner agency, date of sensor installed, location of sensor etc. It does so by collecting, saving, distributing and searching the meta-information resources of the sensor, the USIS then delivers the required meta-information to a service subscriber, while giving data such as location of sensor and sensor name to a manager. The E-R diagram of the UDS metadata consists of a table of sensors network, sensor node, sensor node $\mathrm{H} / \mathrm{W}$ specification, transducer, transducer $\mathrm{H} / \mathrm{W}$ specification, and sensing type specification, and the relationship diagram and detailed definition between each table is covered in the next section[26].

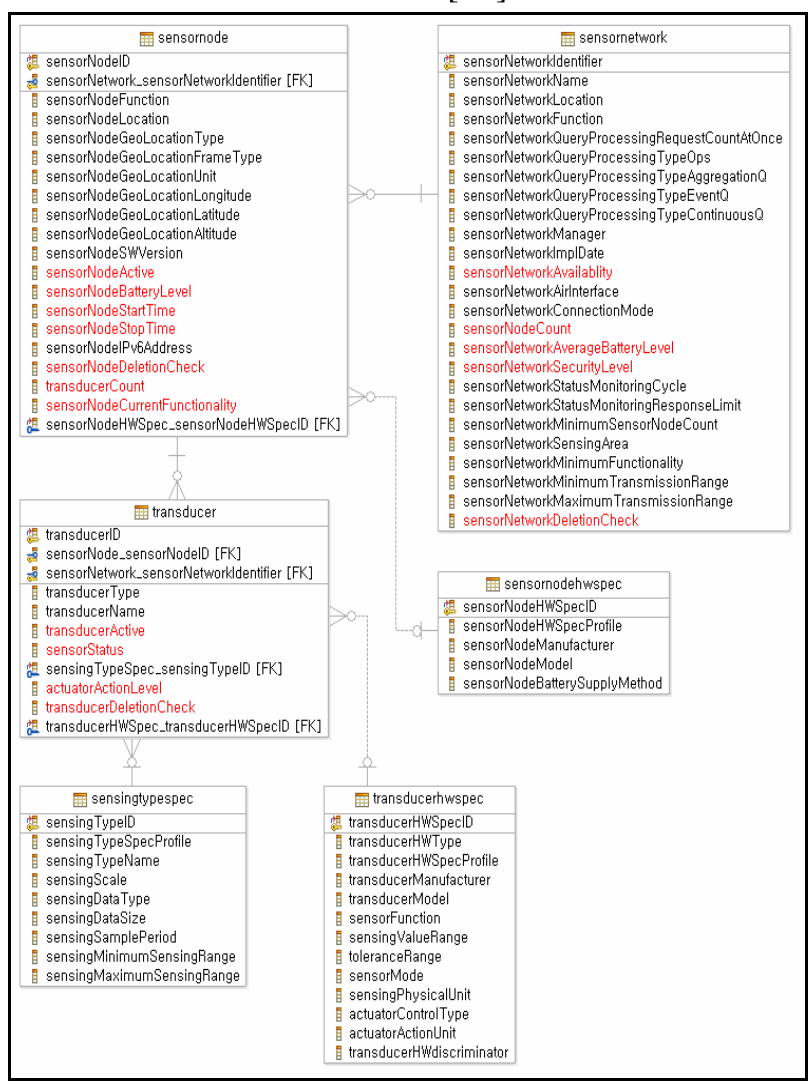

Fig. 3. Relation Diagram of Metadata Table

Fig. 3 shows the E-R diagram of each metadata table. One sensor network in a sensor has $0 \sim n$ sensor nodes, and one sensor node in the sensor network has $0 \sim n$ transducers. In addition, the sensor node has a 0 or 1 sensor node hardware specification, and the transducer has a 0 or 1 transducer H/W specification and sensing type specification[27].

Blue Eyes Intelligence Engineering and Sciences Publication

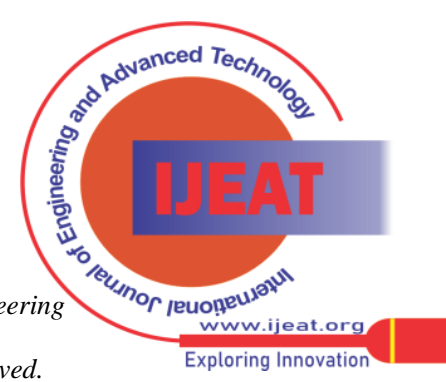


(1) Table relationship between sensor network and sensor node

One of the sensor networks in a sensor has $0 \sim n$ sensor nodes.

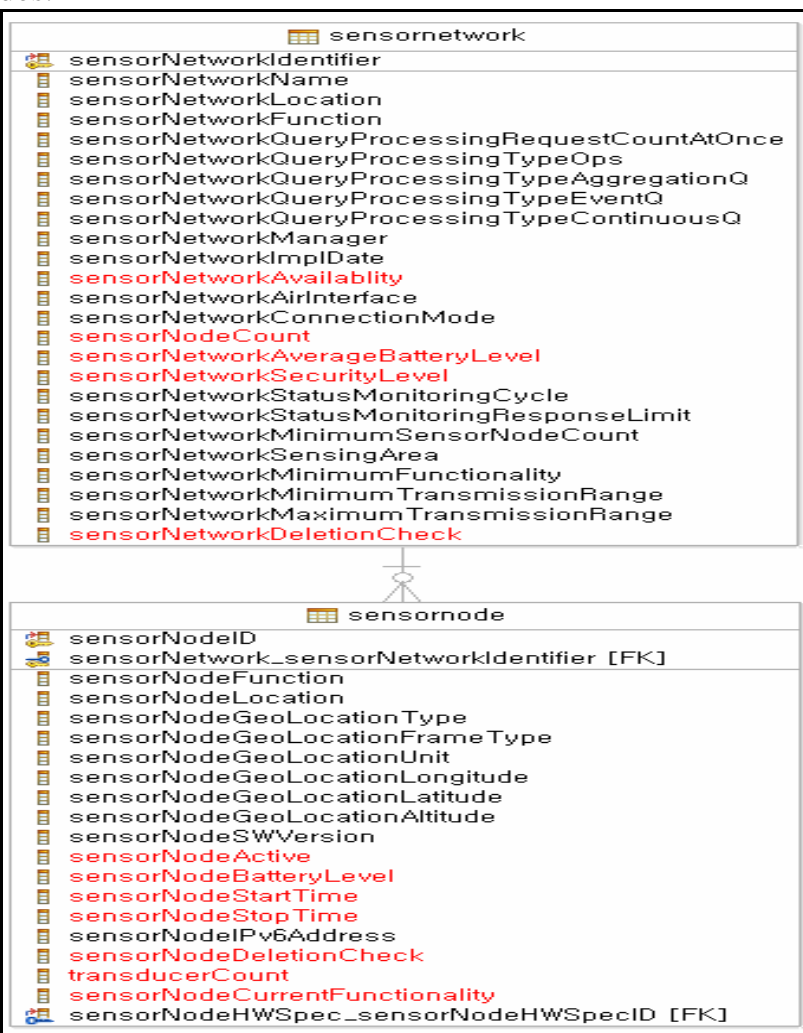

Fig. 4. Table Relationship Diagram of Sensor Network and Sensor Node

Fig. 4 shows the 1:N relationship diagram.

(2) Table relationship between sensor node and transducer

One of the sensor networks in a sensor has $0 \sim n$ transducers.

\begin{tabular}{|c|c|}
\hline 雨 sensornode & \multirow{12}{*}{ 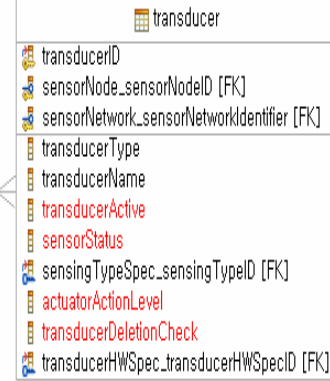 } \\
\hline ins sensorNodelD & \\
\hline sensorNetwork_sensorNetworkdentifier [FK] & \\
\hline 䀚 sensorNodeFunction & \\
\hline 䀚 sensorNodeLocation & \\
\hline I sensorNodeGeoLocationType & \\
\hline 目 sensorNodeGeoLocationFrameType & \\
\hline l sensorNodeGeoLocationUnit & \\
\hline 䀚 sensorNodeGeoLocationLongitude & \\
\hline 首 sensorNodeGeoLocationLatitude & \\
\hline 目 sensorNodeGeoLocationiltitude & \\
\hline l sensorNodeSWVersion & \\
\hline 首 sensorNodeActive & \\
\hline 首 sensorNodeBatteryLevel & \\
\hline 臬 sensorNodeStartime & \\
\hline 貝 sensorNodeStop Time & \\
\hline 貝 sensorNodelPufóddress & \\
\hline I sensorNodeDeletionCheck & \\
\hline $\begin{array}{l}\text { I transducerCount } \\
\text { l sensorNodeCurrentFunctionality }\end{array}$ & \\
\hline in sensorNodeHWSpec_sensorNodeHWSpeclD [FK] & \\
\hline
\end{tabular}

Fig. 5. Table Relationship Diagram of Sensor Node and transducer

Fig. 5 shows the 1:N relationship diagram.

(3) Table relationship between sensor node H/W specification

The sensor node has a 0 or 1 sensor node hardware

Retrieval Number: 100.1/ijeat.F29180810621

DOI:10.35940/ijeat.F2918.0810621

Journal Website: www.ijeat.org specification.

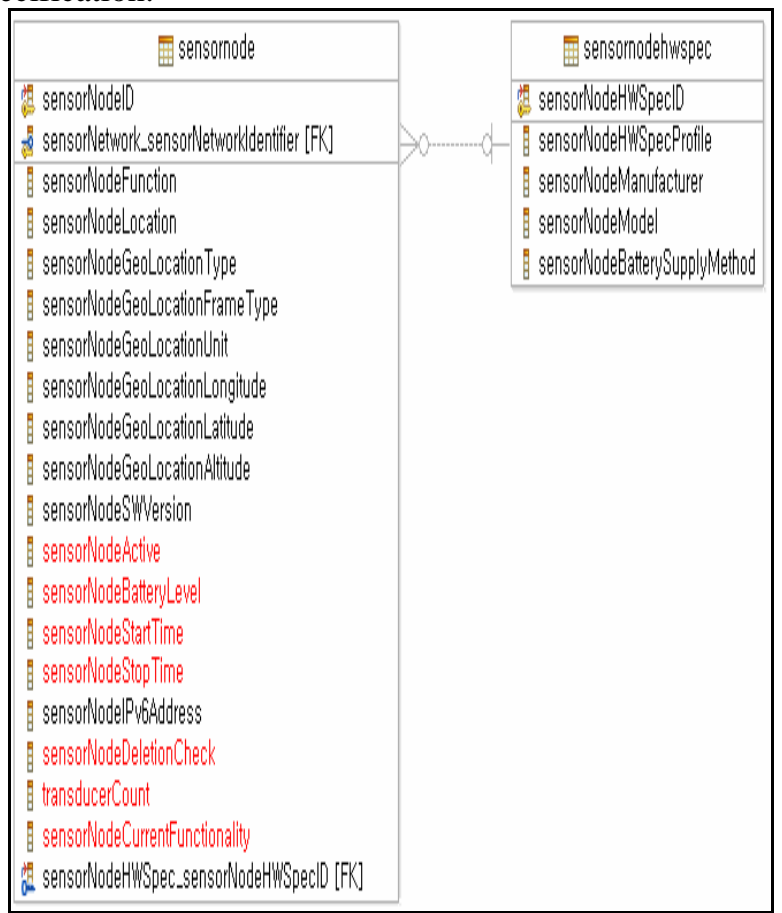

Fig. 6. Table Relationship Diagram of Sensor Node and Sensor Node HWSpec

Fig. 6 shows the 1:N relationship diagram.

(4) Table relationship between transducer and transducer $\mathrm{H} / \mathrm{W}$ specification

The transducer has a 0 or 1 transducer H/W specification.

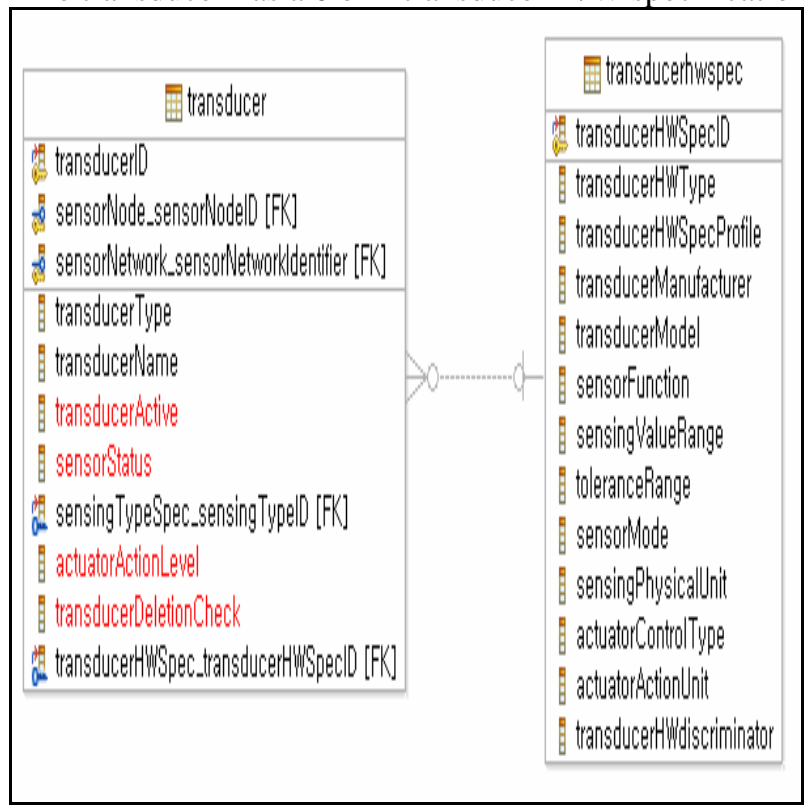

Fig. 7. Table Relationship Diagram of Transducer and Sensor Node HWSpec

Fig. 7 shows the 1:N relationship diagram.

(5) Table relationship between transducer and sensing type specification

The transducer has a 0 or 1 sensing type specification.

Published By:

Blue Eyes Intelligence Engineering

and Sciences Publication

(C) Copyright: All rights reserved.

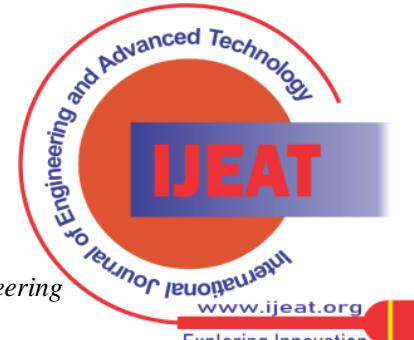

Exploring Innovation 


\section{CONCLUSIONS AND FUTURE WORK}

The research proposed a visual component to effectively express resource information in the sensor web interface that users will encounter in the sensor environment.

Web interface design should provide high quality service to users for their convenience and ease. To meet this ultimate purpose, the interface must exist between users and the many sensors. In addition, the sensor interface should express the information users want in the most efficient way.

First of all, the sensor data is largely divided into sensing data that exchanges sensing information such as temperature, humidity, illuminance, gas, smoke, and fire and metadata for sending and receiving information such as sensor network ID, sensor node ID, and wattage of the sensor nodes. In addition, questions of users are analyzed and classified into several categories to efficiently provide such vast data of sensors to users and then the most suitable visual components are suggested. These visual components largely include texts, images, icons, and graphs, and the advantages and disadvantages of each were examined. We also implemented a web page interface for efficient responses to users' questions by appropriately combining visual components.

The present state of technology related to sensor service, step-by-step service diffusion strategy, and application plan of visualization design that can appear in sensor application service should be studied in future research, which can be presented based on these research results.

In addition, in a number of sensor application fields, a method of application to the interface of all devices including the physical network channel between the web and the outside of a specific device and information devices such as mobile network terminals should be studied.

\section{REFERENCES}

1. Mshali, H.; Lemlouma, T.; Moloney, M.; Magoni, D. A survey on health monitoring systems for health smart homes, International Journal of Industrial Ergonomics, 2018, 66, https://doi.org/10.1016/j.ergon.2018.02.002, pp.26-56.

2. Brumitt, B.; Krumm, J.; Meyers, B.; Shafer, S. Ubiquitous computing and the role of geometry. IEEE Personal Communications. 2020, 7:5, pp.41-43.

3. Cheng, R.; Pravhakar, S. Managing uncertainty in sensor database, ACM SIGMOD Record. 2003, 32:4, pp.41-46.

4. Cheng, R.; Xia, Y.; Prabhakar, S.; Shah, R.; Vitter, J. S. Efficient indexing methods for probabilistic threshold queries over uncertain data, Proceedings of the thirtieth international conference on very large data bases(VLDB' 04). August 2004, 30, pp.876-887.

5. Chvilis, A.; Jensen, C. S.; Pakalnis, S. Techniques for efficient road-network-based tracking of moving objects, IEEE Transactions on Knowledge and Data Engineering. 2005, 17: 5, pp.698-712.

6. Dai, X.; Yiu, M. L.; Mamoulis, N.; Tao, Y.; Vaitis, M. Probabilistic spatial queries on existentially uncertain data. In: Bauzer Medeiros C., Egenhofer M.J., Bertino E. (eds) Advances in spatial and temporal databases. SSTD 2005. Lecture Notes in Computer Science. 2005 3633. Springer, Berlin, Heidelberg. https://doi.org/10.1007/11535331_23, pp.400-417.

7. Hadim, S.; Mohamed, N. Middleware: middleware challenges and approaches for wireless sensor networks, IEEE Distributed Systems Online. March 2006, 7:3, doi: 10.1109/MDSO.2006.19, pp.1-1.

8. Romer, K.; Mattern, F. The design space of wireless sensor networks, IEEE Wireless Communications. Dec 2004, 11:6, https://doi.org/10.1109/MWC.2004.1368897, pp.54-61.

9. Ohta, K.; Isoda, Y.; Jurakake, S. Ubiquitous interface technologies, NTT Technical Review. Nov 2003, 1:8, pp.89-94.

10. Magnus, B.; Anders, L.; Erik, B.; Henrik, E. Distributed use interfaces for clinical ubiquitous computing applications, International Journal of Medical Informatics. Aug 2005, 74:7-8, https://doi.org/10.1016/j.ijmedinf.2005.05.013, pp.545-551.

11. Mainwaring, A.; Culler, D.; Polastre, J.; Szewczyk, R.; Anderson, J. Wireless sensor networks for habitat monitoring, Proceedings of the 1st ACM international workshop on Wireless sensor networks and applications(WSNA '02), ACM, Sensor Networks and Applications, September 2002, https://doi.org/10.1145/570738.570751, pp.88-97.

12. Rajendran, N.; Kamal, P.; Nayak, D.; Rabara, S. A. WATS-SN: A wireless asset tracking system using sensor networks, In Proceedings of 2005 IEEE International Conference on Personal Wireless Communications(ICPWC 2005), New Delhi, India. Jan 2005, https://doi.org/10.1109/ICPWC.2005.1431340, pp.237-243.

13. Tomika, K.; Kondo, K. Ubiquitous sensor network system, NEC Technical Journal. 2006, 1:1, pp.77-82.

14. Engmann, F.; Apietu Katsriku, F.; Abdulai, J. D.; Sarpong Adu-Manu, K.; Kataka Banaseka. F. Prolonging the lifetime of wireless sensor networks: a review of current techniques, Wireless Communications and Mobile Computing, Hindawi. 2018, Article ID 8035065, 23 pages, https://doi.org/10.1155/2018/8035065.

15. Sharif, M.; Sadeghi-Niaraki, A. Ubiquitous sensor network simulation and emulation environments: A survey, Journal of Network and Computer Applications. 2017, 93, pp.150-181

16. Mukherjee, P.; Mukherjee, A. Chapter 1 - Advanced processing techniques and secure architecture for sensor networks in ubiquitous healthcare systems, Volume 5 In Advances in ubiquitous sensing applications for healthcare, Sensors for Health Monitoring, Academic Press. 2019, https://doi.org/10.1016/B978-0-12-819361-7.00001-4 pp. 3-29

17. Tsado, Y.; Lund, D.; A. A. Gamage, K. Resilient communication for smart grid ubiquitous sensor network: State of the art and prospects for next generation, Computer Communications. 2015, 71, pp.34-49.

18. Wang, J.; Cao, J.; Simon Sherratt, R.; Jong Hyuk, P. An improved ant colony optimization-based approach with mobile sink for wireless sensor networks, Journal of Supercomputing. 2018, 74:12, pp.6633-6645.

19. Solon S. Guimarães Jr, C.; de Andrade, M.; Rocha De Avila, F.; Emmanuel De Oliveira Gomes, V.; Camargo Nardelli, V. IoT Architecture for Interoperability and Monitoring of Industrial Nodes, Procedia Manufacturing 2020, 52, https://doi.org/10.1016/j.promfg.2020.11.052., pp.313-318.

20. Dong-Hee, S.; Jaemin, J. Socio-technical analysis of Korea's broadband convergence network: Big plans, big projects, big prospects?, Telecommunications Policy 2012, 36(7), pp.579-593.

21. Kang-Kang, D.; Shuang-Yin, C. Emerging RFID technology in structural engineering - A review, Structures 2020, 28, pp.2404-2414

22. Joseph, S.; J. Joby, N. Analyzing RFID Tags in a Distributed Environment, Procedia Technology 2016, 24, pp.1483-1490.

23. Alfredo J, P.; Sherali, Z.; Nafaa, J. Investigating Security for Ubiquitous Sensor Networks, Procedia Computer Science 2017, 109, pp. 737-744.

24. Zhiwen, Y.; Yunji, L.; Bin, G.; Xingshe, Z.; Hongbo, Ni. Facilitating medication adherence in elderly care using ubiquitous sensors and mobile social networks, Computer Communications 2015, 65, pp.1-9

25. Min, J.; Jingying, Wang. Ubiquitous tutoring in laboratories based on wireless sensor networks, Computers in Human Behavior 2013, 29:2, pp.439-444.

26. Jennifer L. G.; Kaitlyn E. C.; Chantal C. L.; Patrick J. O'C. Novel use of radio frequency identification (RFID) provides a valid measure of indoor stair-based physical activity, Applied Ergonomics 2021, 95, 103431, https://doi.org/10.1016/j.apergo.2021.103431.

27. Krishnan, V. Application of RFID technology in Library: A view, Materials $\quad$ Today: $\quad$ Proceedings 2021, https://doi.org/10.1016/i.matpr.2021.01.584.

28. Ann, Tit, Wan, Y.; Sitsofe, Kwame, Y. Gabriel Nani, Towards an integration framework for promoting electronic procurement and sustainable procurement in the construction industry: A systematic literature review, Journal of Cleaner Production 2020, 250, 119493, https://doi.org/10.1016/j.jclepro.2019.119493.

\section{AUTHORS PROFILE}

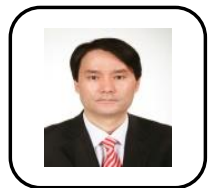

Hyukjun Choi, is a Department of International Logistics at Pyeongtaek University, Korea. His research interests include: e-Commerce, BlockChain, International Trade. His address is: 111 Yongyi-dong, Pyeongtaek-si, Gyeonggi-do 17869 South Korea. His phone number is +82-31-659-8289 and the email address is profchoi@ptu.ac.kr

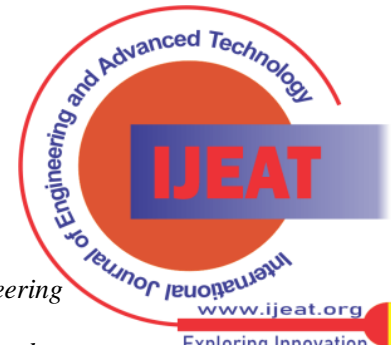


Byeogtae Ahn, is a Faculty of Division of Liberal Arts at Anyang University, Korea. His research interests include: Image Processing, Video Analysis, IoT, BlockChain, Multimedia Database and MPEG-7.

His address is: 37-22, Samduck Minahn-gu Anyang-City Gyeonggi-do, 430-714 South Korea. His phone number is +82-31-463-1204 and the email address is ahnbt@anyang.ac.kr

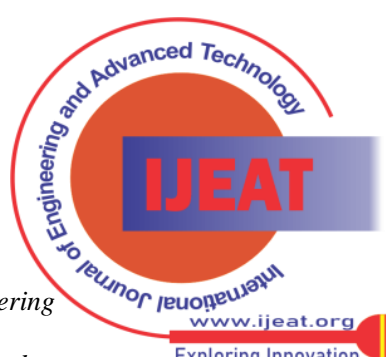

